\title{
Titrating insulin in patients with type 2 diabetes using a structured self-monitoring blood glucose regimen
}

\author{
K L Kalweit, ${ }^{1} \mathrm{MSc} ; \mathrm{D}$ G van Zyl, ${ }^{2} \mathrm{PhD} ;$ P Rheeder, ${ }^{3} \mathrm{PhD}$ \\ ${ }^{1}$ School of Health Systems and Public Health, Faculty of Health Sciences, University of Pretoria, South Africa \\ ${ }^{2}$ Department of Internal Medicine, Kalafong Hospital and School of Medicine, Faculty of Health Sciences, University of Pretoria, South Africa \\ ${ }^{3}$ Department of Internal Medicine, Steve Biko Academic Hospital and School of Medicine, Faculty of Health Sciences, University of Pretoria, South Africa
}

Corresponding author: KL Kalweit (k.kalweit@live.com)

\begin{abstract}
Background. Self-monitoring of blood glucose (SMBG) can inform on the timing of hyperglycaemia, but there is currently no standardised approach to utilising these data to improve glycaemic control in patients with type 2 diabetes.

Objectives. To assess the improvement in glycaemic control when an insulin titration algorithm was used in combination with SMBG in patients with poorly controlled, insulin-treated type 2 diabetes.

Methods. This 6-month prospective study recruited 39 poorly controlled (glycated haemoglobin (HbAlc) $\geq 8.5 \% ; 69.4 \mathrm{mmol} / \mathrm{mol}$ ) type 2 diabetes subjects using twice-daily biphasic insulin from two state hospitals in Tshwane, South Africa. Patients were asked to perform structured SMBG over 4 weeks and return monthly for consultations where physicians titrated insulin doses using an algorithm guided by the data collected. The primary endpoint was the trend in HbAlc measured at baseline and 3 and 6 months.

Results. Mean HbA1c decreased over the study period by $1.89 \%$ (95\% confidence interval (CI) $-2.46--1.33 ; p<0.001)$. The hypoglycaemic event rate $(<4.0 \mathrm{mmol} / \mathrm{L})$ was 33.08 events per patient year. Total daily insulin use increased by a mean of 40.12 units over the study period (standard error 7.7; $p<0.001)$ and weight increased by an average of $3.98 \mathrm{~kg}(95 \%$ CI $2.56-5.41 ; p<0.001)$.

Conclusions. Monthly algorithmic insulin titration guided by structured SMBG can markedly improve glycaemic control in patients with type 2 diabetes by aggressively increasing insulin doses not previously expected in this population, with moderate hypoglycaemic events and weight gain observed.
\end{abstract}

S Afr Med J 2018;108(8):654-659. DOI:10.7196/SAMJ.2018.v108i8.12801

The current gold standard for assessing glycaemic control is measurement of glycated haemoglobin (HbAlc). ${ }^{[1]}$ However, there are numerous caveats associated with using $\mathrm{HbAlc}$ to guide treatment adjustments, including inability to inform on the timing of hyperglycaemia. ${ }^{[2]}$ Additionally, the National Health Laboratory Service allows for HbAlc to be tested twice a year for controlled patients in government healthcare facilities in South Africa (SA) and four times a year for poorly controlled patients, ${ }^{[3]}$ but results are routinely delayed by up to 8 weeks. Infrequent therapy adjustments are therefore being made based on outdated glycaemic data. Selfmonitoring of blood glucose (SMBG) serves as an alternative tool to assess diabetes control and guide more regular medication changes. ${ }^{[4]}$

The purpose of SMBG is to collect detailed information about glucose levels across various time points each day. ${ }^{[2]}$ Most importantly, SMBG data can be made available at each clinical consultation without delay, thus guiding therapy adjustments within the same consultation. ${ }^{[5]}$ However, there is currently no standardised approach to utilising SMBG data to improve glycaemic control in patients with type 2 diabetes. ${ }^{[6]}$ The success of SMBG is expected to be minimal if it is not accompanied by medication dose titration to target specific hyperglycaemic patterns identified. ${ }^{[7]}$

For a variety of conditions, such as HIV or tuberculosis, outcomes with dose titration protocols are superior to those achieved by individualisation of care. ${ }^{[8]}$ This may be true for type 2 diabetes owing to both hesitation of physicians ${ }^{[9]}$ and reluctance of patients ${ }^{[10]}$ to initiate and/or titrate insulin because of the fear of hypoglycaemia and weight gain.

\section{Objectives}

To assess the improvement in glycaemic control when a structured SMBG schedule in combination with an insulin titration algorithm was used for patients with type 2 diabetes. Glycaemic control was primarily investigated by change in $\mathrm{HbAlc}$, and secondly by change in mean SMBG and mean fasting plasma glucose (FPG) levels.

\section{Methods \\ Participants}

The study was a 6-month prospective, non-randomised, single-group trial in patients with type 2 diabetes using twice-daily biphasic human insulin 30 (30\% human insulin and 70\% neutral protamine Hagedorn insulin). Participants were recruited from outpatient diabetic clinics at Steve Biko Academic Hospital and Kalafong Hospital in Tshwane, SA. Each healthcare facility reviewed all patient records to create a list of patients with recorded $\mathrm{HbAlc} \geq 8.5 \%(69.4 \mathrm{mmol} / \mathrm{mol})$ in the preceding 6 months. Patients were then randomly selected from the list and invited to a screening visit via telephone call.

Inclusion criteria were duration of type 2 diabetes $>1$ year, age 18 - 75 years, $\mathrm{HbAlc} \geq 8.5 \%(69.4 \mathrm{mmol} / \mathrm{mol})$, currently treated with $\geq 1$ insulin injection per day and having voluntarily signed the informed consent document. Exclusion criteria were type 1 diabetes, having participated in any other research protocol within the past 30 days, current use of oral hypoglycaemic agents other than metformin, a history of cancer within the past 5 years, current chemotherapy or radiation therapy, plans to relocate or travel extensively during the following 6 months, pregnancy or breastfeeding, $\geq 1$ severe 
hypoglycaemic episode(s) within the past 6 months that resulted in hospital admission and/or coma, severe depression or other severe psychological conditions, a history of chronic kidney disease, a history of heart failure where cardiovascular status was unstable, manual or visual disability that required dependence on others to give insulin or to document blood glucose values, major surgery scheduled within 6 months of enrolment and current use of oral corticosteroids.

Ethical approval was obtained from the Health Sciences Research Ethics Committee of the University of Pretoria (ref. no. 432/2014). The trial was registered with the Department of Health on the South African National Clinical Trials Register (ref. no. DOH-27-0115-4949) and the International Standard Randomised Controlled Trials Number registry (ref. no. ISRCTN13215752).

At the screening appointment, investigators obtained written informed consent before collecting baseline demographic, medical and clinical information, including HbAlc. Patients who met all the inclusion criteria were enrolled into the study until the predetermined sample size was achieved.

\section{Procedures}

The duration of the study was 6 months. Patient visits occurred monthly to coincide with days when the participant came to the hospital to collect their chronic medication. At the baseline visit, patients received a blood glucose meter (Accu-Chek Active blood glucose meter system; Roche Products, SA) and were thoroughly trained in its operation with the aid of pictures to assist those with low literacy levels. Research staff provided patients with test strips and a diary to record blood glucose values as per the structured SMBG routine. Patients were also educated in the use of metered dosing flex pens to administer accurate insulin doses. Assessment of quality of life (QoL) was conducted using the Diabetes Treatment Satisfaction Questionnaire (DTSQ) at baseline and study end. ${ }^{[11]}$ No diabetes-related treatment changes occurred at the baseline visit.

\section{Intervention}

Patients were asked to perform four blood glucose tests per day for 3 consecutive days of each week. Fig. 1A specifies how blood glucose tests were distributed to encompass different time points throughout the day. SMBG testing was staggered to include weekdays and weekends. This resulted in a total of 48 blood glucose tests per
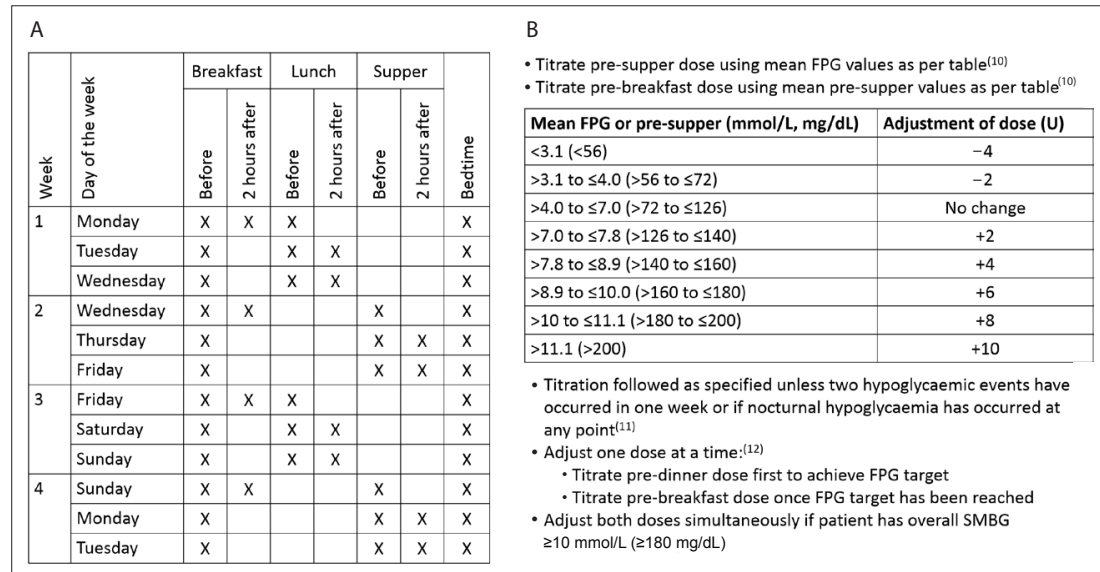

Fig. 1. (A) The newly designed structured SMBG routine with a total of 48 tests performed per month. (B) Insulin titration algorithm used to target hyperglycaemia identified by structured SMBG. (SMBG = self-monitoring of blood glucose; $X=S M B G$ performed; $F P G=$ fasting plasma glucose.)

month. At each consultation, SMBG results were downloaded using the Accu-Chek SmartPix software (Roche Products, SA). SMBG results and targets were discussed with the patient, emphasising the timing of hyperglycaemia.

The insulin titration protocol used by Liebl et al. ${ }^{[12]}$ (p. 47) with aspects from the Canadian Diabetes Association clinical guidelines $^{[13]}$ and the Canadian Agency for Drugs and Technologies in Health report ${ }^{[14]}$ was used to create the algorithm applied in this study, as described in Fig. 1B. Insulin doses were titrated to achieve glycaemic targets; however, if deemed inappropriate by the physician, reasons for not using the algorithm were recorded. If patients had experienced hypoglycaemic events in the preceding month, identification and treatment of low blood glucose was also discussed with the patient. The following glycaemic targets were used: (i) FPG: 5.0 $7.2 \mathrm{mmol} / \mathrm{L}$; (ii) 2-hour post-prandial glucose $<10.0 \mathrm{mmol} / \mathrm{L}$; (iii) average glucose (mean $\mathrm{SMBG})<8.6 \mathrm{mmol} / \mathrm{L}$; and (iv) HbAlc $<7 \%$ (53 $\mathrm{mmol} / \mathrm{mol})$.

\section{Statistical analysis}

The study was designed to have $90 \%$ power to detect an absolute mean withinsubject $\mathrm{HbA} 1 \mathrm{c}$ difference of $1.0 \%$ over the intervention using three observations per patient (baseline and 3 and 6 months). This was determined using the Hotelling-Lawley trace (HLT) test for repeated measures (two-sided, $\alpha=0.05$ ), assuming a mean baseline $\mathrm{HbAlc}$ of $9.0 \%(75 \mathrm{mmol} / \mathrm{mol})$ and standard deviation of $2.2 \% .{ }^{[14]}$ According to these specifications, a sample size of 32 participants with complete data (i.e. all three observations) was needed. To account for missing data and loss to follow-up, a $20 \%$ attrition rate was assumed, resulting in a recommended sample size of 40 participants. By using three observations, the HLT test allowed for a smaller sample size to test the null hypothesis due to repeated HbAlc sampling. In contrast, if only two observations were used (for example, HbAlc at pre- and post-intervention), paired $t$-test analysis would have required 64 patients for the study. Owing to tight budgetary constraints, the HLT test was therefore selected. This choice then necessitated the use of either multivariate analysis of variance (MANOVA) or generalised linear mixed modelling (GLMM) in the analysis of dependent variables with three or more observations. GLMM was favoured over MANOVA owing to its ease in betweensubject covariate handling and increased efficiency in handling missing data. ${ }^{[15]}$

GLMM assumptions include: (i) that the dependent variable (HbAlc) is a normally distributed, continuous variable; (ii) that the residuals of the dependent variable are normally distributed; (iii) that at least $10 \%$ of the total variance in the dependent variable must be explained at the level 2 variable (i.e. patient level in this study); (iv) that the relationship between the mean of the dependent variable and the fixed and random effects can be modelled through a linear function; and $(v)$ that dependent variable variance is not a function of its mean.

The final model conformed to these assumptions, with the exception of normally distributed residuals. Regarding the second assumption, Gelman and Hill ${ }^{[16]}$ note that the normality of residuals does not affect the parameter estimates in multilevel models, and therefore advise against normality tests.

Data for which only two observations were made (pre- and post-intervention) 
were tested using a paired $t$-test if normally distributed (for example, change in weight) or the Wilcoxon signed-rank test if not normally distributed (for example, change in QoL).

\section{Main outcome measures}

$\mathrm{HbAlc}$ was assessed on site using the Cobus B101 (Roche Products, SA) at three time points, namely baseline, 3 months and 6 months. Sensitivity analysis was conducted for participants with a baseline HbAlc $\geq 10 \%(86 \mathrm{mmol} / \mathrm{mol})$. Mean SMBG and mean FPG were assessed per monthly visit over six time periods using the mean of all blood glucose values and the mean SMBG tests performed before breakfast, respectively. Compliance was analysed as a categorical variable where patients were divided into quartiles according to the total number of SMBG tests performed from a maximum of 288 throughout the study period.

The analysis of trend in HbAlc, mean SMBG and mean FPG was performed using GLMM with the XTMIXED command in Stata to assess changes between relative time periods. ${ }^{[17]}$ Participant age, gender, race and number of SMBG tests performed were evaluated as fixed effects; visit number and subject were set as random effects. Random intercept and random slope were modelled for all dependent variable analyses. Based on the mixed model, the least squares estimates of the time interval differences were obtained and tested for statistical significance. No missing data were imputed.

Change in morning and evening insulin doses (pre- and post-intervention) were analysed using paired $t$-test analyses with equal and unequal variance, respectively. Qualitative analysis was undertaken for situations where the algorithm was deemed inappropriate. Change in weight was calculated using a paired $t$-test of differences in baseline and final mass of the participants.

The incidence rate of hypoglycaemic events (defined as blood glucose $<4.0 \mathrm{mmol} / \mathrm{L}$ ) was calculated as [(total number of events across all participants)/ (total duration of treatment in years across all participants)]. Median number of hypoglycaemic episodes was also reported.

Analysis of change in QoL data was assessed from the Likert scale items (range 0 - 6) in the eight-item DTSQ, with higher scores indicating greater treatment satisfaction. Change in treatment satisfaction was calculated as the sum of items 1 and $4-8$ on the DTSQ, and differences in pre- and post-intervention were evaluated using the Wilcoxon signed-rank test. Change in perceived hyperglycaemia (item 2 on the DTSQ) and change in perceived hypoglycaemia (item 3 on the DTSQ) were evaluated using paired $t$-tests for pre- and post-intervention scores.

\section{Results}

A total of 59 patients were screened for the study, of whom 40 were enrolled; 35 were treated at Kalafong District Hospital and 5 at Steve Biko Academic Hospital. Fig. 2 describes the patient flow within the study. One patient was lost to follow-up owing to relocation to a different province after 3 weeks into the study. No insulin titrations were made, so the patient's results were excluded from all calculations. Table 1 describes baseline demographic and clinical characteristics of the 39 patients who completed the trial. There were no intervention-related adverse events.

\section{Glycaemic control}

GLMM analysis revealed that a mean (standard error (SE)) reduction of $1.89 \%$ (0.289) in HbAlc level was achieved over the 6-month intervention (95\% confidence interval (CI) $-2.46--1.33$; $p<0.001)$. Changes in $\mathrm{HbA1c}$ statistics over the various time

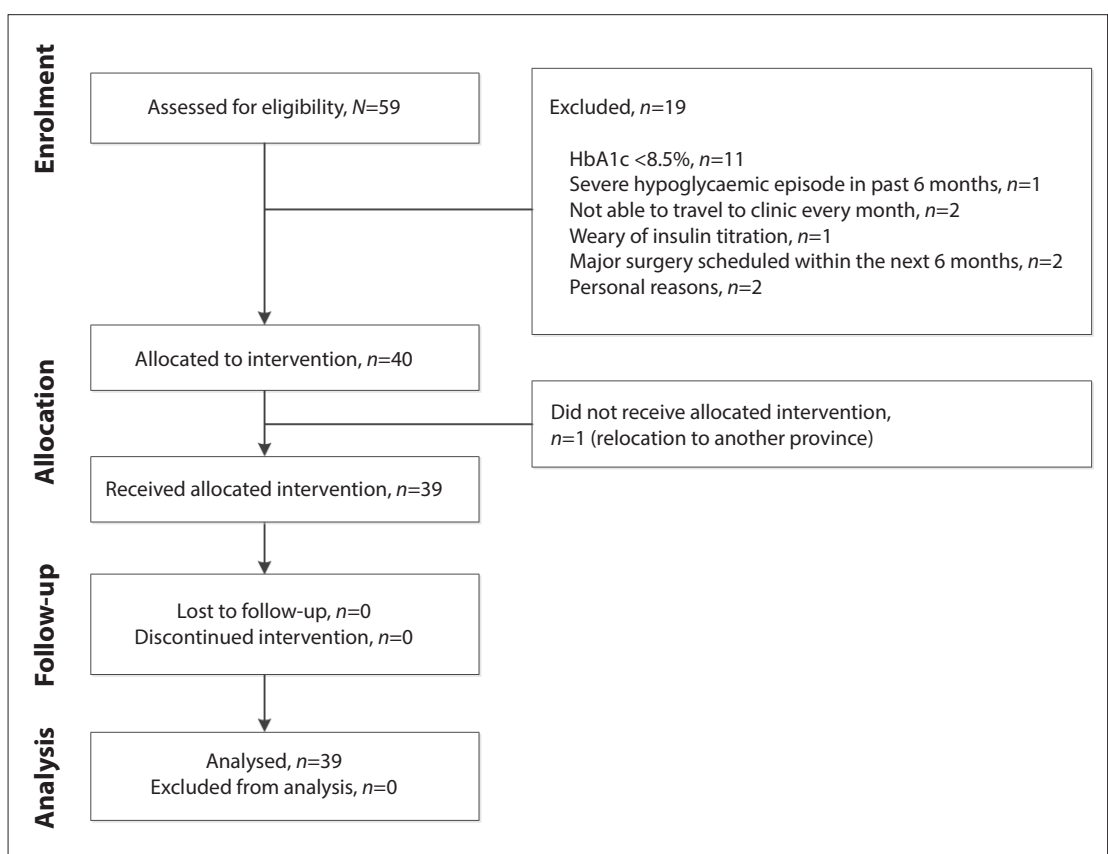

Fig. 2. Patient flow within the study. (HbAlc = glycated haemoglobin.)

Table 1. Baseline demographic and clinical characteristics of the study participants

\begin{tabular}{ll}
\hline Characteristic & Study sample \\
\hline Patient age (years), mean (SD) & $58.8(6.5)$ \\
Male, $n$ (\%) & $13(33.3)$ \\
Ethnicity, $n$ (\%) & \\
$\quad$ Black & $28(71.8)$ \\
White & $4(10.2)$ \\
Coloured & $4(10.2)$ \\
Indian & $3(7.7)$ \\
HbAlc (\%), mean (SD) & $10.69(1.69)$ \\
BMI (kg/m²), mean (SD) & $34.9(7.6)$ \\
Diabetes duration (years), mean (SD) & $17.6(8.2)$ \\
Smoking status, $n$ (\%) & \\
$\quad$ Never & $29(74.4)$ \\
Ex-user & $9(23.1)$ \\
Current & $1(2.5)$ \\
Hypertensives, $n$ (\%) & $37(94.9)$ \\
Hypertension duration (years), mean (SD) & $14.7(9.3)$ \\
SD = standard deviation; HbAlc = glycated haemoglobin; BMI = body mass index.
\end{tabular}


intervals are presented in Table 2. The greatest reduction in HbAlc was achieved in the first 3 months of the intervention. A total of 4 patients $(10.25 \%)$ achieved a target $\mathrm{HbAlc}$ of $<7.0 \%(53 \mathrm{mmol} /$ mol). Sensitivity analysis showed a significantly larger reduction in HbAlc $(-2.29 \%)$ in patients with a baseline HbAlc $\geq 10.0 \%$ ( 86 $\mathrm{mmol} / \mathrm{mol}$ ) in comparison with those with a baseline HbAlc $\leq 9.9 \%$ $(85 \mathrm{mmol} / \mathrm{mol})(-1.26 \% ; p<0.001, \mathrm{GLMM})$. All patients in the sample attended $100 \%$ of the seven clinical visits. Mean patient compliance with the SMBG regimen was $>70 \%$ at each month. No statistically significant difference in $\mathrm{HbAlc}$ reduction was found for patients allocated to different compliance quartiles ( $p=0.062$, GLMM).

Study participants achieved a significant reduction in mean SMBG of $1.6 \mathrm{mmol} / \mathrm{L}$ ( $95 \% \mathrm{CI}-2.5--0.6 ; p=0.002$ ) from a baseline value of $10.9 \mathrm{mmol} / \mathrm{L}$. Fig. 3A shows the trend in mean SMBG with associated 95\% CI for each month of the study. Analysis demonstrated that mean FPG decreased significantly from $9.5 \mathrm{mmol} / \mathrm{L}$ to $8.5 \mathrm{mmol} / \mathrm{L}$ over the study period, resulting in a mean reduction of $1.0 \mathrm{mmol} / \mathrm{L}$

\begin{tabular}{llll}
\multicolumn{3}{l}{ Table 2. Change in HbAlc over various time points } \\
\hline & \multicolumn{3}{c}{ HbAlc (\%) } \\
\cline { 2 - 4 } Time & Mean & SD & Range \\
\hline Baseline & 10.69 & 1.69 & $8.5-14.0^{*}$ \\
3 months & 9.1 & 1.26 & $6.5-12.0$ \\
6 months & 8.8 & 1.42 & $6.7-12.1$ \\
HbAlc = glycated haemoglobin; SD = standard deviation. \\
*The maximum recordable HbAlc on the Cobus B101 was 14.0\%.
\end{tabular}
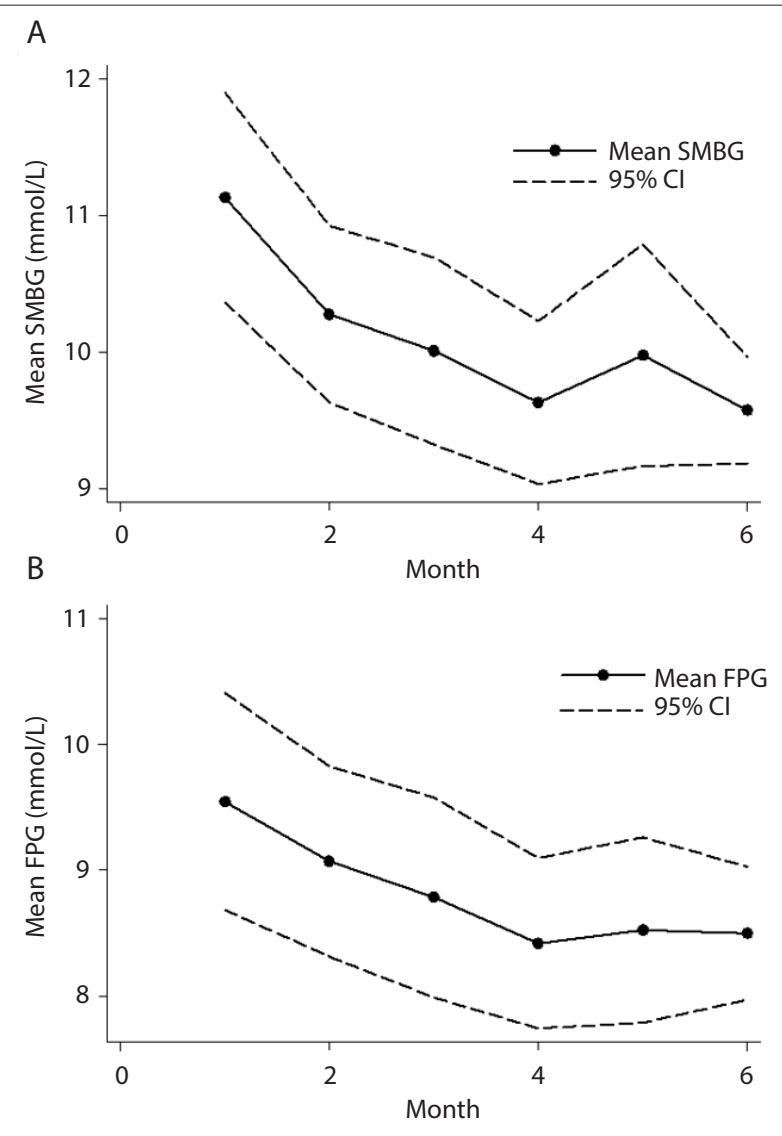

Fig. 3. Changes in (A) mean SMBG and (B) mean FPG over the 6-month study period. Dotted lines show $95 \%$ CIs for values. (SMBG = self-monitoring of blood glucose; $F P G=$ fasting plasma glucose; $C I=$ confidence interval.)
(95\% CI $-2.2--0.2 ; p=0.024)$. Fig. 3B shows the trend in FPG change per month of the study.

\section{Insulin dose}

Paired $t$-test analysis of pre- and post-intervention insulin doses indicated that both mean pre-breakfast and pre-dinner insulin doses increased significantly over the 6-month study period. Table 3 describes these titration changes. Mean total daily insulin was found to increase from 67.76 to 107.89 units (37.19\% increase, SE 7.7; $p<0.001$, unequal paired $t$-test).

Throughout the study period, a total of 234 consultations with insulin titration were performed. Of those consultations, 22 (9.4\%) occurred where it was deemed inappropriate to use the insulin titration algorithm. Reasons for these decisions were grouped into the following: insufficient data to make informed titration decisions $(n=11)$; patient not taking new prescribed doses recommended at the previous visit $(n=4)$; patient taking insulin doses at the incorrect time $(n=3)$; SMBG showing excessive intraday variability $(n=4)$; patient placed on separate regimens for day/night shifts $(n=2)$; and patient diagnosed with renal failure requiring dose reduction $(n=1)$.

The titration algorithm did not allow for sufficient reduction in insulin doses when frequent hypoglycaemia occurred, rather advising that no insulin adjustment be made if two hypoglycaemic events occurred in 1 week or if nocturnal hypoglycaemia had occurred during any point in the previous month (Fig. 1B). Moreover, patients were never observed to have a mean FPG or pre-dinner values of $\leq 4.0 \mathrm{mmol} / \mathrm{L}$ as would be required by the algorithm to decrease the insulin dose. For this reason, it was deemed appropriate to reduce insulin dose by 2 units if three or four hypoglycaemic episodes had occurred at the same meal time during the previous month or by 4 units if five or more hypoglycaemic episodes had occurred at the same meal time.

\section{Hypoglycaemia}

The incidence of hypoglycaemia (defined as $<4.0 \mathrm{mmol} / \mathrm{L}$ ) based on downloaded SMBG data was 33.08 events per patient year, with a median of 13 events per patient (interquartile range 3 - 26) over the 6-month intervention. Eight patients (20.5\%) contributed to $52.7 \%$ of all hypoglycaemic events. Each of these patients had at least 1 month when they experienced $\geq 10$ hypoglycaemic episodes. The majority of the low blood glucose levels occurred in the last 3 months of the trial. Most hypoglycaemic episodes were recorded within the specified SMBG regimen time points. No hypoglycaemic events required hospitalisation, and patients did not require third-party assistance in any event.

\section{Body weight}

Mean weight increased by $3.98 \mathrm{~kg}$ (95\% CI $2.56-5.41 ; p<0.001$, GLMM) over the study period.

Table 3. Titration of insulin doses at each clinical visit

\begin{tabular}{llll}
\hline & \multicolumn{3}{c}{ Mean insulin dose change (units/day) (SD) } \\
\cline { 2 - 4 } Visit & Morning & Evening & Total \\
\hline 1 & $2.0(5.8)$ & $3.64(6.3)$ & $10.0(10.3)$ \\
2 & $5.97(5.2)$ & $4.10(7.1)$ & $10.1(10.0)$ \\
3 & $5.12(4.4)$ & $4.61(5.8)$ & $9.7(8.6)$ \\
4 & $3.15(4.4)$ & $1.59(3.6)$ & $4.7(6.7)$ \\
5 & $2.92(4.4)$ & $2.64(5.3)$ & $5.6(7.6)$ \\
Total & $23.5(12.7)$ & $16.6(20.4)$ & $40.1(28.6)$ \\
SD = standard deviation. & &
\end{tabular}




\section{Quality of life}

The difference in pre- and post-trial treatment satisfaction and perceived hyperglycaemia was found to be non-significant $(p=0.2717$, Wilcoxon signed-rank test; $p=0.1156$, paired $t$-test, respectively). Difference in perceived hypoglycaemia scores was found to be significantly raised after the intervention ( $p=0.0251$, paired $t$-test).

\section{Discussion}

Structured SMBG paired with monthly algorithmic insulin titration was effective in significantly reducing $\mathrm{HbAlc}$ in patients with type 2 diabetes using biphasic insulin. Glycaemic improvement was greatest in patients with a baseline $\mathrm{HbA} 1 \mathrm{c} \geq 10.0 \%(86 \mathrm{mmol} / \mathrm{mol})$.

HbA1c improvement can be attributed to the significant reduction in mean SMBG and mean FPG resulting from increased frequency of insulin titrations. Monnier et al. ${ }^{[18]}$ found that in patients with $\mathrm{HbAlc} \geq 8.4 \%$ ( $\geq 68 \mathrm{mmol} / \mathrm{mol}$ ), overall hyperglycaemia was predominantly attributed to FPG excursions. The improvement in HbAlc achieved in the current study was comparable to ${ }^{[19]}$ and even better than ${ }^{[12,20,21]}$ similar insulin titration studies. Patients with poorer baseline glycaemic control achieved a larger reduction in $\mathrm{HbAlc}$ owing to the larger range over which to improve blood glucose levels before reaching glycaemic targets. Most HbAlc reduction was attributed to the first 3 months of the intervention, as seen in Fig. 3A. During this time, insulin doses were aggressively titrated by using larger (even maximum) dose increments permitted within the algorithm, compared with later dose adjustments. This is expected, as the algorithm allows for smaller adjustments as patients achieve SMBG levels closer to target. It follows that, if resources are severely limited, it may be beneficial to enrol patients into this intervention for only 3 months and still achieve significant glycaemic reductions.

Additional factors that may have contributed to glycaemic improvement are increased frequency of clinical consultations, the use of free meters and strips that were consistently made available, and the practice of downloading SMBG data. This is supported by the fact that four participants had maximum recordable baseline HbAlc values ( $>14 \%$ or $130 \mathrm{mmol} / \mathrm{mol}$ ), yet only one patient had a mean SMBG in the first month to warrant such high glycated haemoglobin levels $(18.9 \mathrm{mmol} / \mathrm{L})$, suggesting that these factors may have been indirectly addressed due to enrolment in the trial. ${ }^{[22]}$

The small reduction in mean SMBG $(-1.6 \mathrm{mmol} / \mathrm{L})$ did not reflect the reduction in $\mathrm{HbAlc}$ achieved over the study period. From the international A1c-Derived Average Glucose trial, a mean reduction in $\mathrm{HbAlc}$ of $1.89 \%$ should have yielded a mean SMBG reduction of $3.0 \mathrm{mmol} / \mathrm{L} \cdot{ }^{[23]}$ It is therefore assumed that total glucose variations were not captured by the SMBG routine, which can be expected, since only 144 glucose measurements per HbAlc measurement were used.

Wei et al. ${ }^{[24]}$ established specific SMBG values throughout the day associated with HbAlc outcomes, and found that for patients who had achieved an HbAlc of $8.0-8.5 \%$ (64 - $69 \mathrm{mmol} / \mathrm{mol})$, mean FPG was estimated as $9.9 \mathrm{mmol} / \mathrm{L}$ (95\% CI $9.1-10.7) .{ }^{[2]}$ This may explain why a relatively small decrease in FPG $(-1.0 \mathrm{mmol} / \mathrm{L})$ in the current study produced moderate changes in $\mathrm{HbAlc}$.

The magnitude of insulin titration was unprecedented, with patients increasing their mean total daily dose by $37.2 \%$ by the end of the study period. The National Institute for Health and Care Excellence indicates that there is no theoretical upper limit to insulin doses. ${ }^{[25]}$ This observation implies that the current standard practice of minor insulin adjustments (for example, adding 2 4 units) made every 3 months is grossly inadequate to achieve improved glycaemia in type 2 diabetes patients on insulin. The large standard deviations seen in Table 3 show the flexibility of the algorithm to accommodate the different needs of each patient.

Most hypoglycaemic events were recorded when patients were scheduled to perform SMBG, so the risk of hypoglycaemia is likely to be under-reported. Additionally, blood glucose levels were not measured during the night, a period when participants were at risk owing to the peak of biphasic insulin action occurring 2 - 4 hours after dinner. ${ }^{[26]}$ A large proportion of hypoglycaemic events were attributed to only eight patients, but they shared no commonalities. The incidence of hypoglycaemia was significantly higher than in other titration studies; however, not all these studies used the conventional definition of $<4.0 \mathrm{mmol} / \mathrm{L}$ to define hypoglycaemia. ${ }^{[12,19,20]}$ Weight gain during the intervention was predicted, as is seen when increasing insulin doses due to a decrease in basal metabolic rate, a decrease in glycosuria, and increased caloric intake for the treatment of hypoglycaemia. ${ }^{[27]} \mathrm{A}$ concern is that the mean $3.98 \mathrm{~kg}$ gain may have a significant impact in terms of increasing risk for cardiovascular disease. ${ }^{[28]}$ Weight gain in the current study was slightly greater than observed in some insulin titration studies, ${ }^{[12,21]}$ but markedly lower than in others. ${ }^{[19,20]}$

The DTSQ identified an increase in perceived burden of hypoglycaemia. This is expected, because increased SMBG frequency may reveal asymptomatic hypoglycaemia and contribute to increased awareness of glucose fluctuations. ${ }^{[29]}$ Patients are also expected to experience more frequent hypoglycaemia as they approach glycaemic targets.

\section{Adjustments to the intervention}

Several changes to both the SMBG regimen and the titration algorithm are recommended. The authors suggest removal of all 12 post-prandial SMBG tests, since none of these results were utilised by the titration algorithm to adjust insulin doses, and patients also found it difficult to remember to test their blood glucose levels 2 hours after eating. Additionally, biphasic insulin is unable to effectively alter post-prandial glucose excursions, which contribute less to overall hyperglycaemia in patients with high HbAlc values. ${ }^{[18]}$ Titration of insulin only required $50 \%$ of SMBG tests to be performed to have sufficient data to inform insulin adjustments. This was shown by equivalent $\mathrm{HbAlc}$ reductions in patients in the second and third quartile of compliance compared with those with enhanced compliance. It was also noted that patients complained of excessive SMBG tests, so reducing the number of prescribed tests may increase compliance. From these arguments, the researchers recommend that the structured SMBG regimen be reduced to a total of 16 tests over a period of 4 days prior to the patient's clinical consultation and/or collection of chronic medication, namely before each main meal and before bedtime each day. This will allow sufficient data on which to titrate insulin doses, accounting for a $70-80 \%$ compliance rate.

The titration algorithm was found to be significantly effective in reducing $\mathrm{HbAlc}$ during the intervention; however, it did not allow for appropriate dose reductions for multiple hypoglycaemic events experienced over the same meal times. As was implemented in the study, if during the previous month patients were found to have 3 - 4 hypoglycaemic events during the same meal time, insulin was reduced by 2 units; patients having $\geq 5$ hypoglycaemic events at the same meal times had dose reductions of 4 units.

\section{Application to clinical practice}

The unprecedented increase in insulin doses for participants in this study points to the novel finding that current insulin titration in patients with type 2 diabetes is vastly inadequate. The advantage 
of this intervention is that an insulin titration algorithm is easy to follow for healthcare professionals who have limited experience with diabetes, while not reducing the doctor's autonomy to override the recommendation set forth. The consistency of care may assist diabetes clinics to efficiently reach glycaemic targets for most patients. Since this study did not enrol patients taking concomitant sulphonylurea agents, the authors recommend caution when applying this titration algorithm to such patients.

\section{Study limitations}

There were several limitations to the study. Firstly, the lack of a control group means that we cannot explicitly state that this intervention truly improved glycaemic control beyond current practice. To confirm the true benefit of this intervention, it is recommended that a sufficiently powered randomised controlled trial be conducted. Secondly, we could not confirm that the recommended insulin titration changes occurred as prescribed. Thirdly, we cannot assess whether improvement of glycaemic control was maintained after the intervention. Lastly, the small sample size limits generalisability of the findings.

\section{Conclusions}

Structured SMBG that advises monthly algorithmic insulin titration can significantly improve glycaemic control in type 2 diabetes patients using twice-daily biphasic insulin by aggressively increasing insulin doses, with moderate hypoglycaemic events and weight gain. This research allows for greater confidence in healthcare practitioners to safely titrate insulin in this population owing to the immense increase in doses observed. It is recommended to assess this study in a cluster randomised clinical trial in order to ensure accuracy and generalisability of results.

Acknowledgements. KLK thanks her mother for her unwavering support throughout this research. Appreciation also goes to Ms Gila Carter for editing assistance, to Prof. David Segal for critique of the clinical significance of the findings herein, and to the staff of Kalafong Diabetes Clinic for their invaluable teaching.

Author contributions. KLK designed the study, directed its implementation, including data collection and quality assurance, and is the primary author. PR assisted with aspects of study design and with statistical analysis and edited the manuscript. DGvZ assisted with patient recruitment and data collection and edited the manuscript.

Funding. The financial assistance of the National Research Foundation (NRF) towards this research is hereby acknowledged. Opinions expressed and conclusions arrived at are those of the authors and are not necessarily to be attributed to the NRF. Appreciation also goes to the School of Health Systems and Public Health and the School of Medicine, University of Pretoria, for their funding contribution of this project. KLK also thanks Roche Products (South Africa) for their enormous generosity in terms of financial and product contributions that made this project possible.

Conflicts of interest. KLK is employed by the non-profit organisation Youth With Diabetes to which Roche Diagnostics contributes financial and product donations in order for the organisation to run camps for children with diabetes. PR and DGvZ have no potential conflicts of interest relevant to this article to declare.

1. The Diabetes Control and Complications Trial Research Group. The effect of intensive treatment of diabetes on the development and progression of long-term complications in insulin-dependent diabetes diabetes on the development and progression of long-term complications in insulin-dependen
mellitus. N Engl J Med 1993;329(14):977-986. https://doi.org/10.1056/nejm199309303291401

2. Institute of Health Economics. Consensus Statement on Self-monitoring in Diabetes. Alberta, Canada: 2. Institute of Health Economics. Consensus Statement on Self-monitoring in Diabetes. Alberta, Canada:
Institute of Health Economics. Updated 2006. http://www.ihe.ca/documents/consensus_statement_ complete_nov17_0.pdf (accessed 9 January 2015).

3. National Department of Health, South Africa. Essential Drugs Programme: Hospital Level (Adults) Standard Treatment Guidelines and Essential Medicines List. Chapter 8 - Endocrine System: Diabetes mellitus. 4th ed. Pretoria: NDoH, 2015. http://www.health.gov.za/index.php/standard-treatmentguidelines-and-essential-medicines-list/category/286-hospital-level-adults?download=2409:hospitallevel-adult-2015-v5-0 (accessed 9 January 2016).

4. Benjamin EM. Self-monitoring of blood glucose: the basics. Clin Diabetes 2002;20(1):45-47. https://doi. org/10.2337/diaclin.20.1.45

5. Sheu WH. Addressing self-monitoring of blood glucose: Advocating paired glycemic testing for people with type 2 diabetes. J Diabetes Investig 2012;3(4):337-338. https://oi.org/10.1111/j.20401124.2012.00216.x

6. American Diabetes Association. Standards of medical care in diabetes - 2014. Diabetes Care 2014;37(Suppl 1):S14-S80. https://doi.org/10.2337/dc14-s014 7. Canadian Optimal Medication Prescribing and Utilization Service. Cost-Effectiveness of Blood Glucose
Test Strips in the Management of Adult Patients with Diabetes Mellitus. Ottawa: Canadian Agency for Drugs and Technologies in Health, 2009:3(3). https://www.cadth.ca/media/pdf/BGTS_Consolidated_ Economic_Report.pdf (accessed 15 January 2016).

8. Hirsch IB, Bergenstal RM, Parkin CG, Wright E, Buse JB. A real-world approach to insulin therapy in primary care practice. Clin Diabetes 2005;23(2):78-86. https://doi.org/10.2337/diaclin.23.2.78

9. Daniels A, Biesma R, Otten J, et al. Ambivalence of primary health care professionals towards the South African guidelines for hypertension and diabetes. S Afr Med J 2000;90(12):1206-1211.

10. Hunt LM, Valenzuela MA, Pugh JA. NIDDM patients' fears and hopes about insulin therapy: The basis of patient reluctance. Diabetes Care 1997;20(3):292-298. https://doi.org/10.2337/diacare.20.3.292

11. Lewis $\mathrm{K}$, Bradley C, Knight G, Boulton A, Ward J. A measure of treatment satisfaction designed specifically for people with insulin-dependent diabetes. Diabet Med 1988;5(3):235-242. https://doi. specifically for people with insulin-dex
$\mathrm{org} / 10.1111 / j .1464-5491.1988 . t b 00976 . x$

12. Liebl A, Prager R, Binz K, Kaiser M, Bergenstal R, Gallwitz B. Comparison of insulin analogue regimens in people with type 2 diabetes mellitus in the PREFER Study: A randomized controlled trial. Diabetes
in pention in people with type 2 diabetes mellitus in the PREFER Study: A randomized co
Obes Metab 2009;11(1):45-52. https://doi.org/10.1111/j.1463-1326.2008.00915.x

13. Harper W, Clement M, Goldenberg R, Hanna A, Main A, Retnakaran R, Canadian Diabetes Association Clinical Practice Guidelines Expert Committee. Pharmacologic management of type 2 diabetes. Can J Diabetes 2013;37(Suppl 1):S61-S68. https://doi.org/10.1016/j.jcjd.2013.01.021

14. Kreidler SM, Muller KE, Grunwald GK, et al. GLIMMPSE: Online power computation for linear models with and without a baseline covariate. J Stat Softw 2013;54(10). https://doi.org/10.18637/jss.v054.i10

15. Truxillo C. The punchline: MANOVA or a mixed model? 2011. https://blogs.sas.com/content/ sastraining/2011/02/02/the-punchline-manova-or-a-mixed-model (accessed 11 December 2017).

16. Gelman A, Hill J. Data Analysis Using Regression and Multilevel/Hierarchical Models. Cambridge: Cambridge University Press, 2007

17. StataCorp. Stata Statistical Software: Release 12. College Station, Tex.: StataCorp LP, 2011.

18. Monnier L, Lapinski $\mathrm{H}$, Colette $\mathrm{C}$. Contributions of fasting and postprandial plasma glucose increments to the overall diurnal hyperglycemia of type 2 diabetic patients: Variations with increasing levels of $\mathrm{HbA}(1 \mathrm{c})$. Diabetes Care 2003;26(3):881-885. https://doi.org/10.2337/diacare.26.3.881

19. Garber A, Wahlen J, Wahl T, et al. Attainment of glycaemic goals in type 2 diabetes with once-, twice-, . Garber A, Wahlen , Wahl, et al. Attainment of glycaemic goals in type 2 diabetes with once-, twice-,
or thrice-daily dosing with biphasic insulin aspart $70 / 30$ (the 1-2-3 study). Diabetes Obes Metab or thrice-daily dosing with biphasic insulin aspart 70/30 (the $1-2-3$
2006;8(1):58-66. https://doi.org/10.1111/.1463-1326.2005.00563.x

20. Holman RR, Thorne KI, Farmer AJ, et al. Addition of biphasic, prandial, or basal insulin to oral therapy in type 2 diabetes. N Engl J Med 2007;357(17):1716-1730. https:///doi.org/10.1056/nejmoa075392

21. Janka HU, Plewe G, Riddle MC, Kliebe-Frisch C, Schweitzer MA, Yki-Jarvinen H. Comparison of basal insulin added to oral agents versus twice-daily premixed insulin as initial insulin therapy for type 2 diabetes. Diabetes Care 2005;28(2):254-259. https://doi.org/10.2337/diacare.28.2.254

22. McCarney R, Warner J, Iliffe S, van Haselen R, Griffin M, Fisher P. The Hawthorne effect: A randomised, controlled trial. BMC Med Res Methodol 2007;7(1):1. https://doi.org/10.1186/1471-2288-7-30

23. Nathan DM, Kuenen J, Borg R, Zheng H, Schoenfeld D, Heine RJ, Alc-Derived Average Glucose Study Group. Translating the AlC assay into estimated average glucose values. Diabetes Care 2008;31(8):14731478. https://doi.org/10.2337/dc08-0545

24. Wei N, Zheng H, Nathan DM. Empirically establishing blood glucose targets to achieve HbAlc goals. Diabetes Care 2014:37(4):1048-1051. https://doi.org/10.2337/dc13-2173

25. Sibal L, Home PD. Management of type 2 diabetes: NICE guidelines. Clin Med 2009;9(4):353-357. https://doi.org/10.7861/clinmedicine.9-4-353

26. Hermansen K, Colombo M, Storgaard H, Ostergaard A, Kolendorf K, Madsbad S. Improved postprandial . Hermansen K, Colombo M, Storgaard H, Ostergaard A, Kolendorf K, Madsbad S. Improved postprandial
glycemic control with biphasic insulin aspart relative to biphasic insulin lispro and biphasic human insulin in patients with type 2 diabetes. Diabetes Care 2002;25(5):883-888. https://doi.org/10.2337/ diacare.25.5.883

27. Mäkimattila S, Nikkilä K, Yki-Järvinen H. Causes of weight gain during insulin therapy with and without metformin in patients with type II diabetes mellitus. Diabetologia 1999;42(4):406-412. https://doi. org/10.1007/s001250051172

28. Gerstein HC, Riddle MC, Kendall DM, et al. Glycemia treatment strategies in the Action to Control Cardiovascular Risk in Diabetes (ACCORD) trial. Am J Cardiol 2007;99(12):S34-S43. https://doi. org/10.1016/j.amjcard.2007.03.004

29. IDF Clinical Guidelines Taskforce and SMBG International Working Group. Global Guideline on Selfmonitoring of Blood Glucose in Non-insulin Treated Type 2 Diabetes. Brussels, Belgium: International Diabetes Federation, 2009.

Accepted 1 February 2018 